\title{
A Hypergravity Environment Induced by Centrifugation Alters Plant Cell Proliferation and Growth in an Opposite Way to Microgravity
}

\author{
Ana I. Manzano • Raúl Herranz • \\ Jack J. W. A. van Loon - F. Javier Medina
}

Received: 2 December 2011 / Accepted: 26 February 2012 / Published online: 3 June 2012

(C) The Author(s) 2012. This article is published with open access at SpringerLink.com

\begin{abstract}
Seeds of Arabidopsis thaliana were exposed to hypergravity environments $(2 g$ and $6 g$ ) and germinated during centrifugation. Seedlings grew for 2 and 4 days before fixation. In all cases, comparisons were performed against an internal (subjected to rotational vibrations and other factors of the machine) and an external control at $1 g$. On seedlings grown in hypergravity the total length and the root length were measured. The cortical root meristematic cells were analyzed to investigate the alterations in cell proliferation, which were quantified by counting the number of cells per millimeter in the specific cell files, and cell growth, which were appraised through the rate of ribosome biogenesis, assessed by morphological and morphometrical parameters of the nucleolus. The expression of cyclin B1, a key regulator of entry in mitosis, was assessed by the use of a CYCB1:GUS genetic construction. The
\end{abstract}

Electronic supplementary material The online version of this article (doi:10.1007/s12217-012-9301-1) contains supplementary material, which is available to authorized users.

\footnotetext{
A. I. Manzano · R. Herranz · F. J. Medina ( $\square)$

Centro de Investigaciones Biológicas (CSIC), Ramiro de

Maeztu, 9 28040-E, Madrid, Spain

e-mail: fjmedina@cib.csic.es

R. Herranz $(\varangle)$ · J. J. W. A. van Loon

European Space Research \& Technology Center-European Space Agency (ESTEC-ESA), Noordwijk, Netherlands

e-mail: r.herranz@csic.es

J. J. W. A. van Loon

Dutch Experiment Support Center (DESC) @ OCB-ACTA,

VU-University Amsterdam, Amsterdam, Netherlands
}

results showed significant differences in some of these parameters when comparing the $1 g$ internal rotational control with the $1 g$ external control, indicating that the machine by itself was a source of alterations. When the effect of hypergravity was isolated from other environmental factors, by comparing the experimental conditions with the rotational control, cell proliferation appeared depleted, cell growth was increased and there was an enhanced expression of cyclin B1. The functional meaning of these effects is that cell proliferation and cell growth, which are strictly associated functions under normal $1 g$ ground conditions, are uncoupled under hypergravity. This uncoupling was also described by us in previous experiments as an effect of microgravity, but in an opposite way. Furthermore, root meristems appear thicker in hypergravity-treated than in control samples, which can be related to changes in the cell wall induced by altered gravity.

Keywords Arabidopsis • Cell cycle • Nucleolus • Altered gravity

\section{Introduction}

All living organisms are well-adapted to the different conditions on Earth, including the gravity force. Longterm modifications of this parameter would undoubtedly lead to evolutionary changes, whereas physiological changes are expected for short-term alterations in the gravity vector. In addition to space flight, ground based facilities are used to create altered gravity environments, both simulating microgravity on a random positioning machine (RPM) by clinorotation (Van Loon 2007) and increasing gravitational load 
in hypergravity habitats produced by centrifugation (Van Loon et al. 2008).

Although a lot of research efforts have been dedicated to microgravity research, hypergravity is an unavoidable partner in this endeavour, being part of spaceflights during rockets or spacecrafts launching and reappearing upon recovery of samples to the Earth or an eventual travel to the Moon or Mars. Modification of the $g$ vector quantity by centrifugation is also needed to simulate other celestial bodies' gravitational loads different from $1 g$ force on Earth. Also, during parabolic flights, hypergravity periods alternate with microgravity ones. Therefore, it is highly advisable to be capable of detecting and isolating the effects of both types of altered gravity environments.

Previous experiments on the effects of hypergravity on plants have described the reorientation of microtubules in the epidermic layer of cells of the Arabidopsis hypocotyls (Hoson et al. 2010; Soga et al. 1999). Other authors have shown that hypergravity produces changes in the cell surface, intracellular transduction pathways and in the localization of subcellular organelles (Ingber 2006; Monshausen and Sievers 2002; Nickerson et al. 2004)

The processes of growth, differentiation and development affect the whole plant, but they rely on cellular mechanisms, including cell proliferation and growth, which are basic and essential functions for the cell life. It is well known that signals transduced between different plant organs are capable of activating key modulators of cell growth and cell division in a coordinated manner, in meristems; the reception of these signals and the response to them is indeed called "meristematic competence" (Mizukami 2001). Furthermore, cell proliferation at the root meristem constitutes the source of cells for root growth and differentiation and the cellular basis for the developmental program of the plant (Dolan et al. 1993; Scheres et al. 2002).

The alteration of environmental conditions such as gravity can modulate the activity of meristematic cells (Medina and Herranz 2010). Results obtained in space experiments have shown that cell proliferation parameters are modified in plants grown in space, including maize (Barmicheva et al. 1989), lentils (Darbelley et al. 1989) and also Arabidopsis (Matía et al. 2010), in which a decoupling between cell growth and cell proliferation in meristems has been observed in four day-long experiments (from seed hydration to chemical fixation) performed in the International Space Station. Therefore, it seems clear that microgravity induces some perturbations in plant development, but it is important to consider that plants can also be sensitive to other stresses associated with the environmental conditions present in spacecrafts (Ferl et al. 2002). For that reason, the effects of altered gravity on plant development have also been observed in seedlings grown in microgravity simulators. An increased growth rate of primary and lateral roots and an earlier initiation of secondary roots were shown in clinorotated seedlings, leading to an increase in biomass (Hilaire et al. 1996) and a similar decoupling of cell proliferation and growth in the meristems was observed in both real and simulated (RPM) microgravity (Matía et al. 2010).

This paper reports the results of two hypergravity experiments (at $2 g$ and $6 g$ ) carried out in a centrifuge, consisting of seed germination, seedling growth for 2 and 4 days and chemical fixation of samples, accompanied by an external and a rotational $1 g$ controls. All of the ulterior analyses were performed in the three cellular layers of the cortical cylinder of the root meristem, namely epidermis, cortex and endodermis (Scheres et al. 2002). These cells are specialized in proliferation, such that their only functional program is to grow and divide continuously at a rate three times higher than in the central cylinder (Fujie et al. 1993). In this zone of the root tip, we analyzed a series of cellular parameters that are highly reliable indicators of the status of proliferation and growth of cells in order to assess variations in these functions prompted by a change in gravity conditions.

Regarding proliferation, we measured the number of cells per millimeter in meristematic cell layers; the rate of increase of this parameter was called "rate of local cell production" (Beemster and Baskin 1998). As an additional proliferation parameter we determined cyclin B1 expression levels (by means of a CycB1:GUS transgenic line). We have chosen this transgenic construct because cyclin B1 is a key regulator of the G2/M transition (Schnittger et al. 2002; Weingartner et al. 2004) potentially involved in the microgravity related proliferation/growth decoupling (Matía et al. 2009).

Regarding cell growth, we have determined the nucleolar size and the relative amount and distribution of nucleolar subcomponents, such as the fibrillar centers (FCs) and the granular component (GC). In the meristem, cell growth is determined largely by the activity of RNA polymerase I, which controls ribosomal RNA synthesis and ribosome biogenesis in the nucleolus (Baserga 2007). A unequivocal functional linkage exists between the rate of ribosome biogenesis and the nucleolus ultrastructure demonstrated in several cellular model systems (Hernandez-Verdun 2006; Raska et al. 2006; Thiry and Goessens 1996) and, in particular, in plants (Medina et al. 2000; Sáez-Vasquez and Medina 2008; Shaw and Doonan 2005) always using cellular models characterized by high cell proliferating activity. 


\section{Materials and Methods}

The results presented in this paper correspond to an experiment performed in the Large Diameter Centrifuge (LDC), a dedicated facility for hypergravity research located at ESTEC (ESA) research center in Noordwijk (The Netherlands).

\section{Hypergravity Experiment Design}

Seeds of Arabidopsis thaliana (L.), Heynh., ecotype "Columbia" (Col-0) carrying a CycB1:GUS reporter gene construction (Ferreira et al. 1994), kindly supplied by Dr. E. Carnero-Diaz (UPMC, Paris, France), which had been stored for at least two days at $4^{\circ} \mathrm{C}$ for stratification, were sterilized in $1.25 \%(\mathrm{v} / \mathrm{v})$ sodium hypochlorite and $1 \%(\mathrm{v} / \mathrm{v})$ Triton X-100 for $10 \mathrm{~min}$ and washed before placing them on $9 \mathrm{~cm}$ diameter Petri dishes containing $0.5 \%$ agar with MS (Murashige and Skoog's, Duchefa) plant culture medium. They were preserved at $4^{\circ} \mathrm{C}$ for two days until loading them into the LDC.

Seeds were allowed to germinate within the LDC gondolas by incubating them at $24^{\circ} \mathrm{C}$, while the LDC was running at either $2 g$ or $6 g$ generating speed. A rotational control experiment $(1 g)$ was placed in the central gondola and, additionally a $1 g$ external control was performed out of the centrifuge, in the same temperature-controlled room. After 2 or 4 days growing in dark conditions, samples were quickly recovered from the dishes, photographed and plunged into the fixative solution $(3 \%(\mathrm{v} / \mathrm{v})$ glutaraldehyde for ultrastructural microscopical analyses, or $90 \%$ acetone for GUS staining). The time elapsed between removal of samples from LDC and fixation did not exceed $30 \mathrm{~min}$.

\section{Sample Processing for CycB1-GUS Analysis}

Samples were incubated in acetone at $-20^{\circ} \mathrm{C}$ for $24 \mathrm{~h}$ (including transportation to Madrid, Spain). Then, samples were washed with $100 \mathrm{mM}$ phosphate buffer and the GUS signal was revealed by enzymatic reaction ( $5 \mathrm{mM}$ potassium ferrocyanide and ferricyanide, $100 \mathrm{mM}$ phosphate buffer and $40 \mathrm{mM} \mathrm{X}$-Glc A) in the dark. Seedlings were washed and mounted in $8 \times$ $8 \mathrm{~mm}$ well slides and observed under a Leica DM2500 microscope. Images were digitally recorded with a Leica DFC320 CCD camera and processed with QWin Standard (Leica Microsystems) and Image J 2.0 (imagejdev.org) softwares. Integrated optical density (IOD) was calculated as the product of the stained area by the
Optical Density (OD) in the blue light spectrum. An unstained zone of the root tip was used as blank.

Sample Processing for Ultrastructural Analysis

Samples were fixed in 3\% glutaraldehyde for 1 hour at RT, transferred to PBS for washing (3 times, $10 \mathrm{~min}$ ) and partially dehydrated in an ethanol series until $70 \%$ ethanol; in this medium they were transported to Madrid, Spain, for final processing for microscopy, including full dehydration, methylation-acetylation and embedding in LR White resin (London Resin Co., UK).

Microscopy, Immunocytochemistry and Quantification

From resin-embedded materials, semithin sections, $2 \mu \mathrm{m}$ thick, were obtained and observed unstained under a Leica DM2500 microscope equipped with phase contrast. Images were digitally recorded with a Leica DFC320 CCD camera. For ultrastructural studies, ultrathin sections were mounted on Formvarcoated nickel grids stained with uranyl acetate and lead citrate and observed in a Jeol 1230 electron microscope, operating at $100 \mathrm{kV}$. Prior to observation, grids were counterstained with uranyl acetate, either alone or followed by lead citrate.

Quantitative measurements (seedling and root length, number of cells per $\mathrm{mm}$ in root cell files, crosssectional area of nucleoli and proportion of nucleolar granular component (GC)) were carried out on digital images using the quantization software "QWin Standard" (Leica Microsystems).

\section{Statistical Analyses Methodology}

Measurements of cell parameters were performed on root meristematic cells belonging to the epidermal, cortical and endodermal cell layers of the root. The number of samples measured was: 20 seedlings for seedling length, 10 roots for number of cells per $\mathrm{mm}, 60$ nucleoli (light microscopy) for cross-sectional area and 15 nucleoli (electron microscopy) for GC proportion. Statistical analysis of data was performed using SPSS 13.0 software. Description of quantitative variables was performed using mean and standard deviation values after checking normality with the Kolmogorov-Smirnov test. Mean values were compared using the Student $t$-test for independent samples; differences were considered significant for a bilateral value lower than 0.05 . 
Fig. 1 Macroscopical morphology parameters of seedlings. a, b Seedling and root lengths and $\mathbf{c}, \mathbf{d}$ Root meristem thickness. a, c: Two-day LDC experiment. b, d Four-day LDC experiment. Statistically significant differences $(p<0.05)$ have been indicated with * (versus $1 g$ external control) or with \# (versus $1 g$ rotational control). Differences in length were found between $1 g$ controls ( 2 days) and also in all samples within LDC (4 days)
A) Length in $\mathrm{mm}$ after 2 days

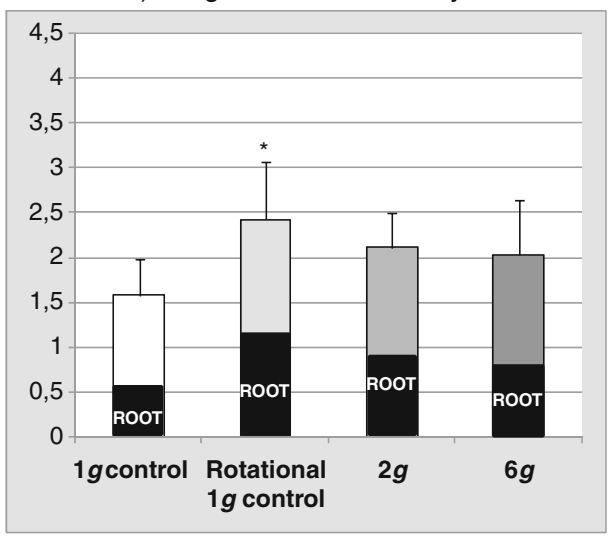

C) Root meristem thickness in $\mu$ m after 2 days

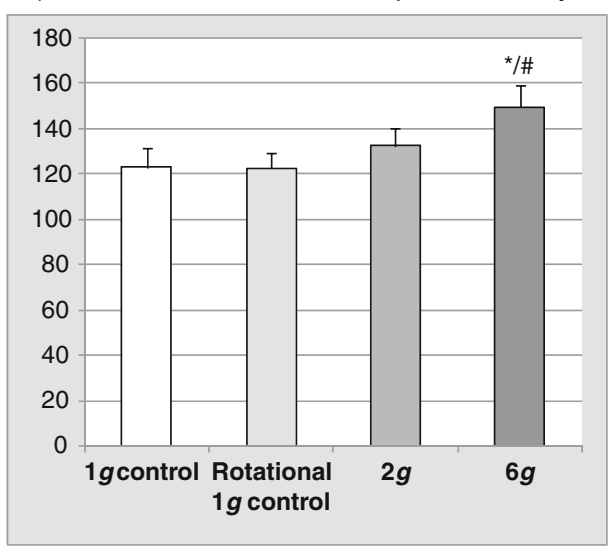

B) Length in $\mathrm{mm}$ after 4 days

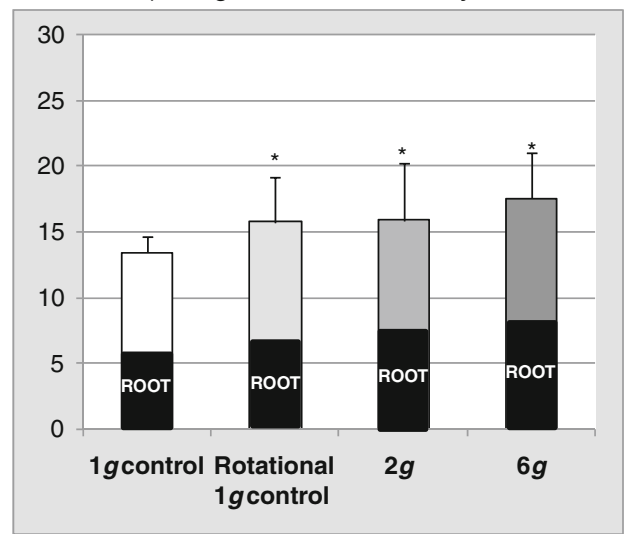

D) Root meristem thickness in $\mu$ m after 4 days

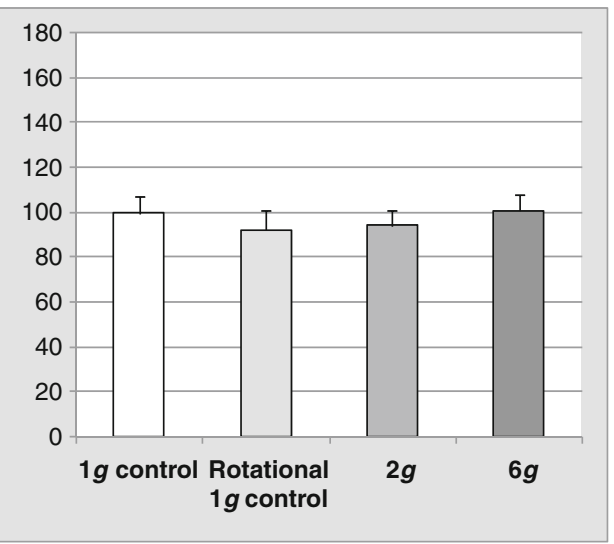

\section{Results}

Morphometric Analysis of the Seedlings and Root Meristems

Seedling length after 2 and 4 days of growth was used as the first criteria for cell growth and proliferation events. No significant differences were found at
2 days except between $1 g$ controls, maybe due to the mechanical stress, vibrations and slight differences in temperature in the rotational control position (near the main engine of LDC) (Fig. 1a). However, at 4 days, both $2 g$ and $6 g$ samples were significantly longer than $1 g$ external control samples $(p<0.05)$. Nevertheless, a similar difference was found also between external and rotational $1 g$ controls. The evaluation of the root
Fig. 2 Local cell proliferation rate $(\mathrm{cell} / \mathrm{mm})$. a 2 days-long LDC experiment. b 4 days-long LDC experiment. Statistically significant differences $(p<0.05)$ have been indicated with an * (versus $1 g$ control) or with an \# (versus $1 g$ rotational control). Differences have not been found between $1 g$ controls and mainly in the 2 days experiment
A) Cells $/ \mathrm{mm}$ after 2 days

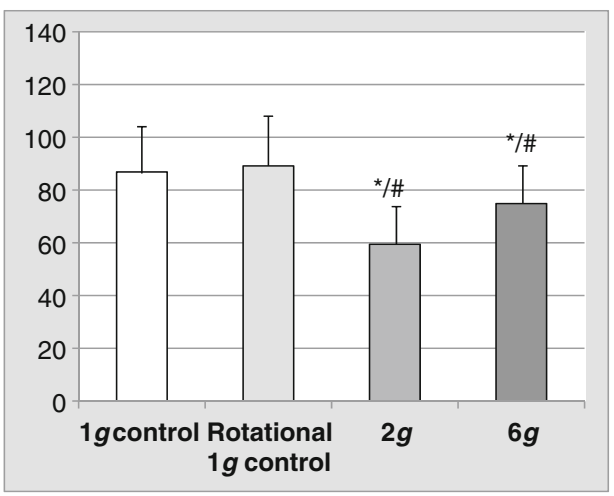

B) Cells $/ \mathrm{mm}$ after 4 days

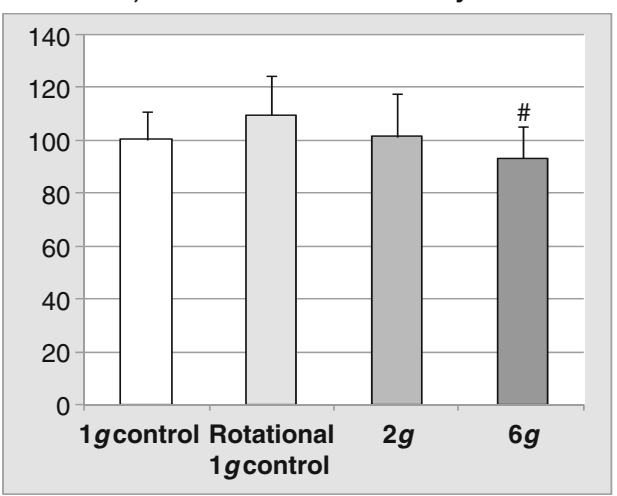


length did not offer any significant result, different from the seedling length (Fig. 1 and Supplementary material Fig. S1). In $2 \mu \mathrm{m}$ sections obtained from roots embedded in LR White resin we determined under the light microscope the meristem thickness $(\mu \mathrm{m})$, local cell proliferation rate (cells $/ \mathrm{mm})$ and nucleolar size (area in $\mu \mathrm{m}^{2}$ ). In general, meristem thickness was higher in all hypergravity samples in comparison with $1 \mathrm{~g}$ controls, although statistical significance was only reached for the $6 g$ sample, 2 days after germination (Fig. 1c). Differences in the rate of local cell production, as an estimation of the proliferation rate, were determined by counting the number of cells in the cortical cylinder layers (Fig. 2 and supplementary material Fig. S2). This parameter showed no variations between $1 g$ controls and a reduction in cell proliferation at both $g$ levels 2 days after germination, that almost disappeared after 4 days (remaining significant only when comparing the $1 g$ rotational control versus the $6 g$ experiment). Finally, nucleolus size, as an indicator of the rate of ribosome biogenesis and, indirectly, of cell growth, was assessed (Fig. 3). At both 2 and 4 days after germination it was observed a reduction in the nucleolus size under hypergravity versus
Fig. 3 a, b Average size of the nucleolus (area in $\mu \mathrm{m}^{2}$ ) and percentage of Granular Component (GC).

a Two-day-long LDC experiment. b Four-day-long LDC experiment. Statistically significant differences $(p<$ $0.05)$ have been indicated with * (versus $1 g$ control) or with \# (versus $1 g$ rotational control). Differences have been found between $1 g$ controls but also in the hypergravity positions that show an intermediate effect, different from both controls. c. Nucleolar ultrastructure. Examples of the 2 day-long LDC experiment nucleolus images by electron microscopy. Different components of the nucleolus (GC, granular component, DFC, dense fibrillar component, $\mathrm{V}$, internal vacuole and arrows indicating fibrillar centers) show no variations under hypergravity
A) Nucleolus Area in $\mu m^{2}$ after 2 days

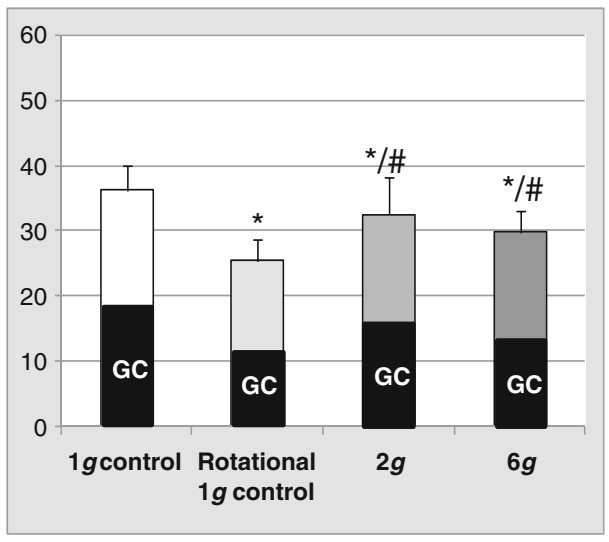

B) Nucleolus Area in $\mu m^{2}$ after 4 days

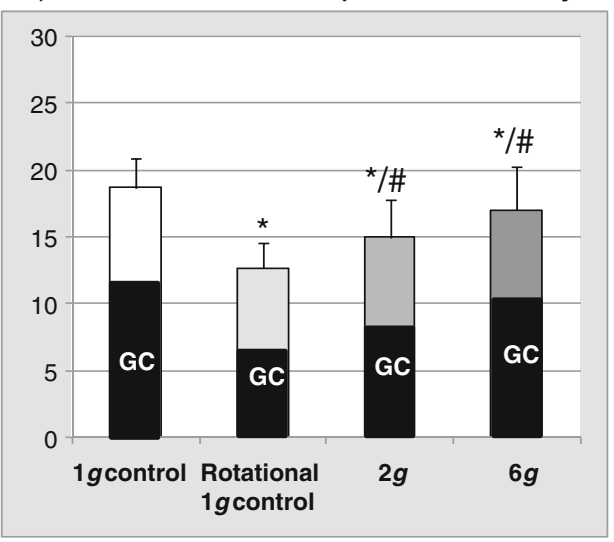

C)
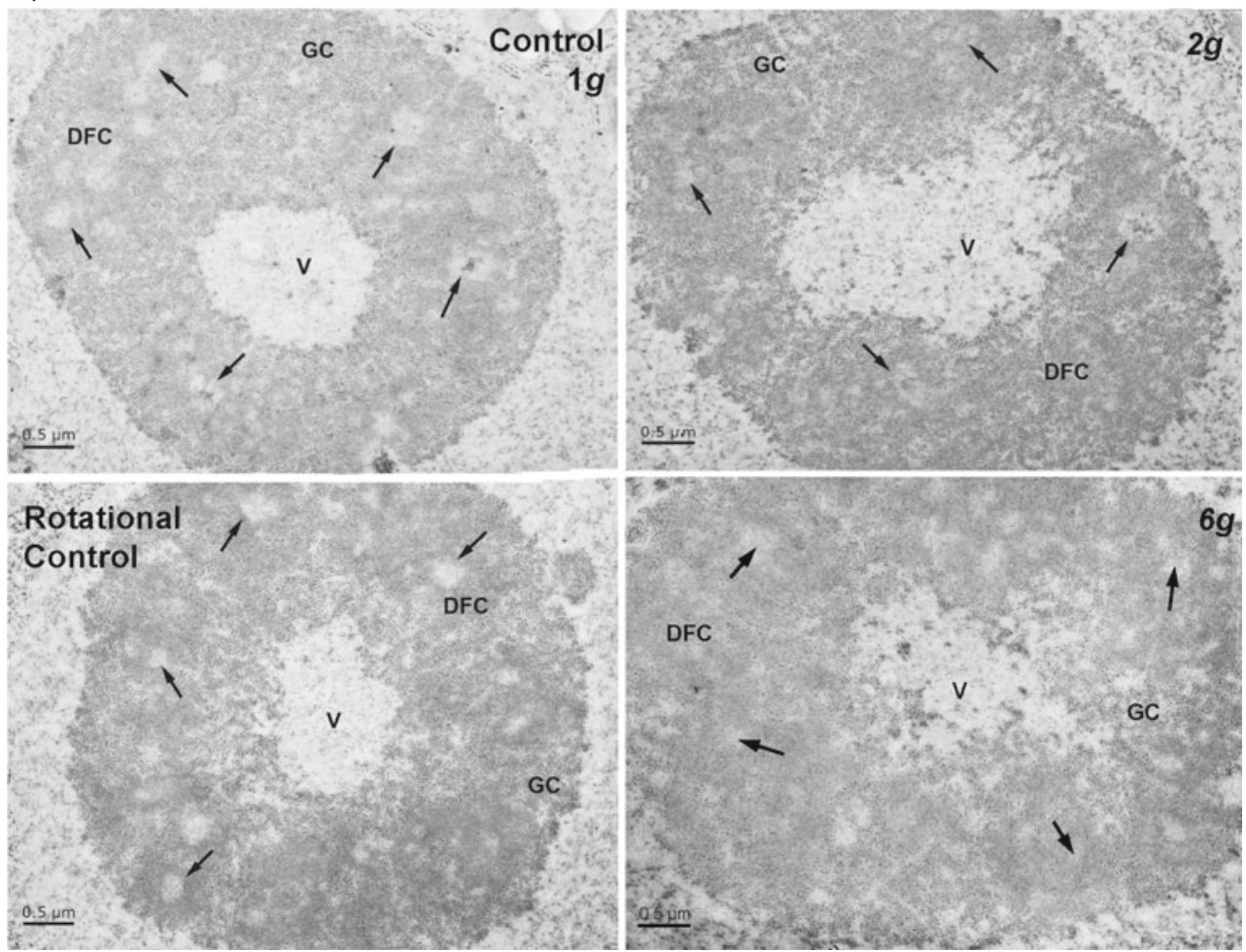
Fig. 4 GUS staining revealing Cyclin B1 expression levels. a Two-day-long and b Four-day-long LDC experiments optical microscopy staining in the root meristems exposed to $1 g$ external control, $1 g$ rotational control, $2 g$ and $6 g$ conditions (from left to right). c Two-day-long and d Four-day-long LDC experiments I.O.D. (integrated optical density) quantification. Statistically significant differences $(p<0.05)$ have been indicated with * (versus $1 g$ control) or with \# (versus $1 g$ rotational control)
A)
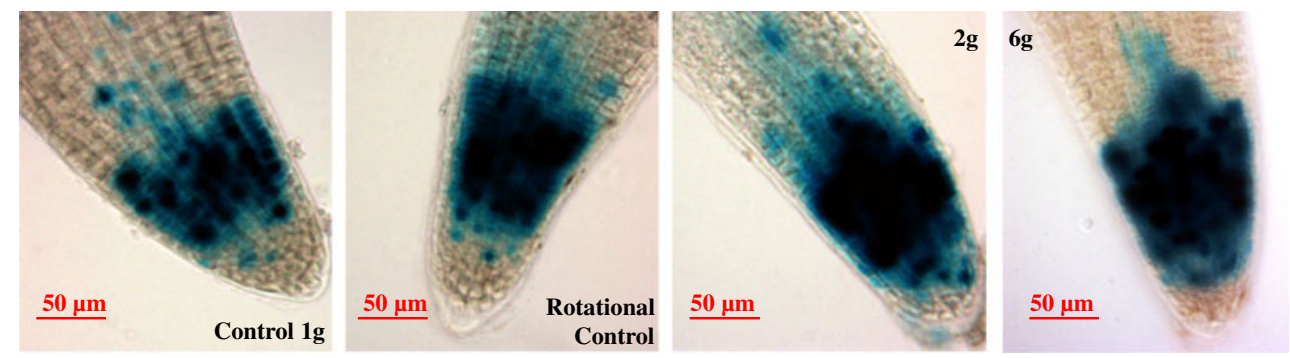

B)
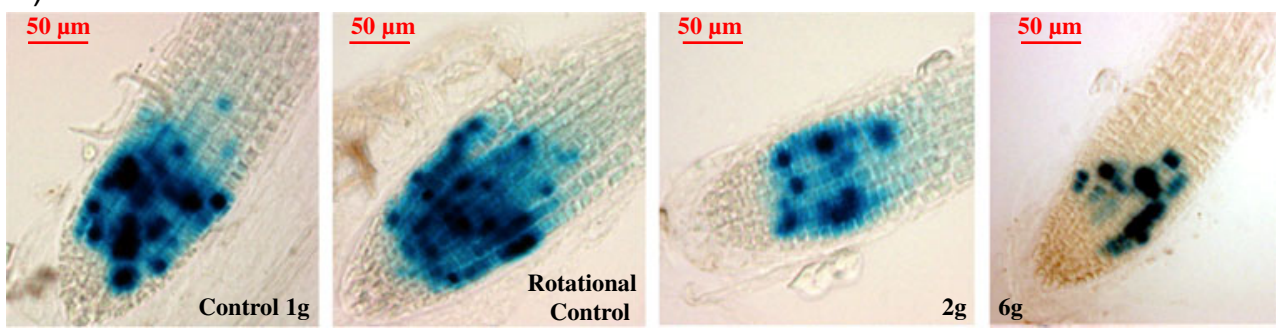

D) I.O.D. (CycB1) after 4 days

C) I.O.D. (CycB1) after 2 days

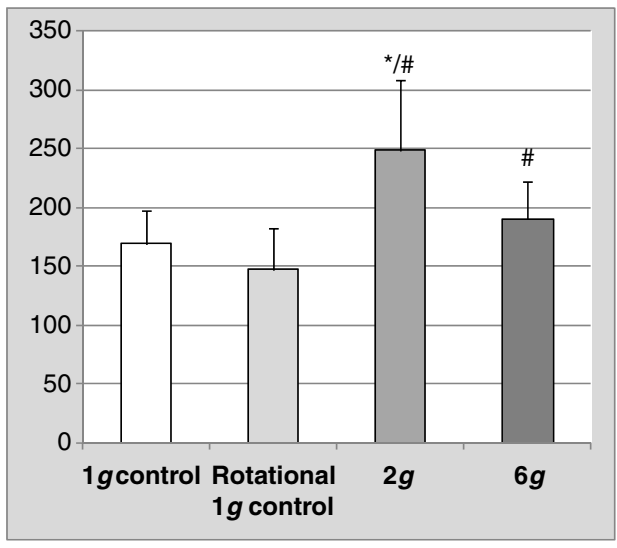

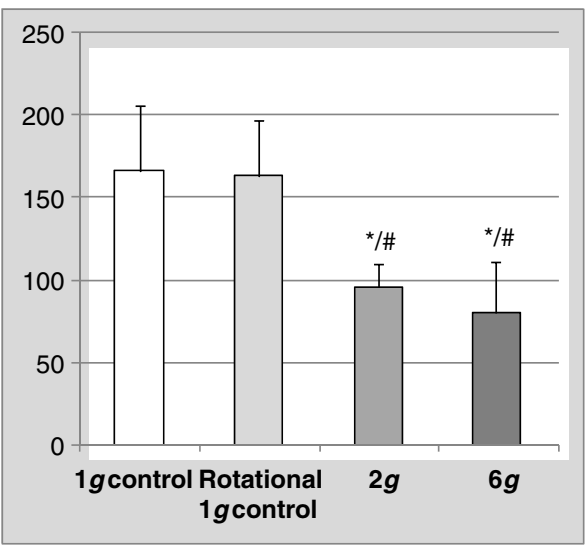

external $1 g$ control, but the size of the nucleolus appeared even smaller in the $1 g$ rotational control samples. We did not detect any difference in the proportion or distribution of the internal components of the nucleolus (Fig. 3c and supplementary material Fig. S3).

Table 1 Summary of the results obtained with CYCB1:GUS seedlings exposed to hypergravity $(2 g / 6 g)$ versus $1 g$ external (1 $g$ C.) and rotational (Rotat C.) controls

\begin{tabular}{|c|c|c|c|c|c|c|}
\hline \multirow[t]{2}{*}{ Parameter } & \multirow{2}{*}{$\begin{array}{l}\text { Days from } \\
\text { germination }\end{array}$} & \multirow{2}{*}{$\begin{array}{l}\text { Rotat C. } v s \\
1 g \text { C. }\end{array}$} & \multicolumn{2}{|l|}{$2 g v s$} & \multicolumn{2}{|l|}{$6 g v s$} \\
\hline & & & $1 g \mathrm{C}$. & Rotat C. & $1 g \mathrm{C}$. & Rotat C. \\
\hline Seedling length & 2 days & + & $=$ & $=$ & $=$ & $=$ \\
\hline Local Cell Proliferation Rate & & $=$ & -- & -- & -- & -- \\
\hline Ribosome biogenesis (Nucleolar size) & & -- & - & ++ & -- & ++ \\
\hline Cyclin B1 expression & & $=$ & ++ & ++ & $=$ & + \\
\hline Seedling length & 4 days & ++ & ++ & $=$ & ++ & $=$ \\
\hline Local Cell Proliferation Rate & & $=$ & $=$ & $=$ & $=$ & -- \\
\hline Ribosome biogenesis (Nucleolar size) & & -- & - & ++ & - & ++ \\
\hline Cyclin B1 expression & & $=$ & -- & -- & -- & -- \\
\hline
\end{tabular}

Statistically significant differences have been indicated with + (increase) or - (decrease) when $p<0.05$ and with $++/--$ when $p<$ 0.01. $=$ indicates non-significant differences 
Regulation of Cell Cycle Progression, Determined by the Expression Levels of Cyclin B1, Estimated by GUS Reporter Gene

The expression of the cyclin B1 gene was estimated by the use of the genetic construction CycB1:GUS, by means of the quantification of the intensity of GUS staining (Fig. 4). Cyclin B1 is a key regulator of the $\mathrm{G} 2 / \mathrm{M}$ transition of the cell cycle, and this gene is specifically expressed in G2, indirectly indicating the rate of entry into mitosis; therefore, it is usually considered as a good marker of cell division (ColonCarmona et al. 1999). Using the integrated optical density parameter to quantify CYCB1 driven GUS signal, a statistically significant increase in cyclin B1 expression levels was found 2 days after germination into the LDC and the opposite effect was observed in the 4 days after germination samples (Fig. 4). As a summary, we have collected all variations observed for the different parameters that we have used to evaluate the cell proliferation / cell growth status of the seedlings exposed to the two hypergravity positions that we have used $(2 g / 6 g)$ and the two $1 g$ control positions (Table 1).

\section{Discussion}

Our experiment of seedling growth in conditions of hypergravity has shown that some important parameters of cell growth and proliferation appear affected by this alteration of the gravitational status of the environment. However, not all the changes that we have found in these parameters, when comparing the results of the experimental conditions with the control $1 g$ experiment under normal environmental conditions outside the centrifuge, can be attributed to altered gravity. Interestingly, some environmental constrains included in the $1 g$ rotational control (vibration, temperature, pressure) are capable of affecting our model system without the need of any change in the $g$ level. In fact, significant differences have been found between the $1 g$ external control and the $1 g$ rotational control, which can be attributed to factors present in the machine used for hypergravity production.

If we compare the experimental results obtained in hypergravity conditions with the rotational $1 \mathrm{~g}$ control, we find a similar, but opposite effect to the results found in real and simulated microgravity (Matía et al. 2010, 2009), including a decrease in proliferation rates, an increase in cyclin B1 as a marker of G2/M transition (only at the 2-day stage), and an increase in the nucleolar size. These effects can be attributed exclusively to gravity alteration, since the changes due to other factors of the machine are already considered and assumed in the rotational control experiment. However, these changes observed in the centrifuge, due to hypergravity, are milder in comparison to previous results observed in real or simulated microgravity (Matía et al. 2009, 2010). At this respect, it is especially interesting the change in the expression of cyclin B1. Under microgravity conditions, an increase in the expression of this gene was detected, in apparent contradiction with the decrease in the cell proliferation rate (Matía et al. 2009); in our experiment in hypergravity, this apparent contradiction also exists in the opposite sense (decrease in proliferation rate and increase in cyclin B1 expression), although it can only be detected at the 2-day stage, whereas samples of 4 days show a more coherent behavior of these two parameters. Furthermore, effects observed at either $2 g$ or $6 g$ level are very similar to each other, so we can conclude that hypergravity causes a relatively weak decoupling of the cell growth and proliferation parameters.

Growth alterations due to cell cycle modifications, including transient $\mathrm{G} 2 / \mathrm{M}$ arrest, were observed after exposing the fission yeast $S$. pombe to hypergravity (Soto et al. 2007). Alterations in the actin-polarization pattern, caused by phosphorylation (activation) of the MAP kinase Sty1, which is induced by gravitational stress, can be related to this process. On the other side, accumulation of cyclin B1 in the mutant tonsoku can be related with a prolongation of G2 stage caused by activation of cell cycle arresting proteins (Suzuki et al. 2005). Cell cycle arrest in the S-phase under stress conditions has been demonstrated for plants grown under UV-B, altered osmolarity and genotoxicity conditions, showing smaller tissues with fewer cells (Adachi et al. 2011; Galbraith et al. 1991; Skirycz et al. 2011). In this case, the increase of $C Y C B 1$ expression is an indicator of cell cycle arrest.

Another intriguing result is the significant increase in root meristem thickness, which appears in samples grown for two days, especially at $6 g$. A possible explanation for this effect would be that it is the consequence of modifications in the cell wall, which becomes shorter, thicker and more rigid due to the accumulation of xyloglucans, as a countermeasure against the additional gravitational force (Soga 2004). Furthermore, it has been shown that hypergravity promotes an increase in Arabidopsis thaliana secondary cell wall lignifications (Tamaoki et al. 2006).

In conclusion, we have shown in this and previous papers that the root meristem is sensitive to changes in the intensity of the environmental gravity vector, even though no specific mechanisms for gravity sensing have 
been detected up till now in root meristematic cells. Two key features of meristematic cells, namely cell proliferation and cell growth, whose strict coordination is responsible of the meristematic competence of these cells, appear altered and uncoupled as an effect of gravity alteration, either when the vector is suppressed (microgravity), or when it is enhanced (hypergravity). Therefore, discoupling of these processes seems to be a specific effect of the gravitational stress, since it has not been described as a usual response to other types of abiotic stress (thermal, saline and irradiation). Interestingly, studies of transgenic lines have demonstrated that cell division and cell growth could be coordinated by multiple mechanisms. Thus, decrease or inhibition of one of these processes would be compensated by an increased activity of the other and vice versa (Ferjani et al. 2007).

Acknowledgements The present research would not have been possible without the technical support from the section TEC-MMG at ESTEC, especially Mr. Robert Lindner and Mrs. Jutta Krause and Environmental Biology Department at CIB (CSIC), especially Mrs. Mercedes Carnota. AIM was supported by a Spanish FPI fellowship program. RH was supported by a Spanish Science and Technology (Especializacion en Organismos Internacionales) / CDTI scholarship (ESA Spanish trainee program) and also supported by a CSIC JAE-Doc contract. This work was supported by Grants from the Spanish "Plan Nacional de Investigación Científica y Desarrollo Tecnológico" Ref. AYA2009-07952/ESP and AYA2010-11834-E to FJM, from the Dutch Organisation of Scientific research (NWO) \#MG-057 to JvL and by the access to the Ground Based Facilities: ESA SEGMGSPE_Ph1 Project to JvL, FJM and RH.

Open Access This article is distributed under the terms of the Creative Commons Attribution License which permits any use, distribution, and reproduction in any medium, provided the original author(s) and the source are credited.

\section{References}

Adachi, S., Minamisawa, K., Okushima, Y., Inagaki, S., Yoshiyama, K., Kondou, Y., Kaminuma, E., Kawashima, M., Toyoda, T., Matsui, M., Kurihara, D., Matsunaga, S., Umeda, M.: Programmed induction of endoreduplication by DNA double-strand breaks in arabidopsis. Proc. Natl. Acad. Sci. U.S.A. 108(24), 10004-10009 (2011). doi:10. 1073/Pnas.1103584108

Barmicheva, E.M., Grif, V.G., Taïrbekov, M.G.: Growth and structure of cells in the maize root apex under space flight conditions. Cytology 31, 1324-1328 (1989)

Baserga, R.: Is cell size important? Cell Cycle 6(7), 814-816 (2007)

Beemster, G.T., Baskin, T.I.: Analysis of cell division and elongation underlying the developmental acceleration of root growth in Arabidopsis thaliana. Plant Physiol. 116(4), 15151526 (1998)
Colon-Carmona, A., You, R., Haimovitch-Gal, T., Doerner, P.: Spatio-temporal analysis of mitotic activity with a labile cyclin-gus fusion protein. Plant J. 20(4), 503-508 (1999)

Darbelley, N., Driss-Ecole, D., Perbal, G.: Elongation and mitotic activity of cortical cells in lentil roots grown in microgravity. Plant Physiol. Biochem. 27, 341-347 (1989)

Dolan, L., Janmaat, K., Willemsen, V., Linstead, P., Poethig, S., Roberts, K., Scheres, B.: Cellular organisation of the Arabidopsis thaliana root. Development 119(1), 71-84 (1993)

Ferjani, A., Horiguchi, G., Yano, S., Tsukaya, H.: Analysis of leaf development in fugu mutants of arabidopsis reveals three compensation modes that modulate cell expansion in determinate organs. Plant Physiol. 144(2), 988-999 (2007). doi:10.1104/Pp.107.099325

Ferl, R., Wheeler, R., Levine, H.G., Paul, A.L.: Plants in space. Curr. Opin. Plant Biol. 5(3), 258-263 (2002)

Ferreira, P., Hemerly, A.S., De Almeida Engler, J., Bergounioux, C., Burssens, S., Van Montagu, M., Engler, G., Inzé, D.: Three discrete classes of arabidopsis cyclins are expressed during different intervals of the cell cycle. Proc. Natl. Acad. Sci. U.S.A. 91, 11313-11317 (1994)

Fujie, M., Kuroiwa, H., Suzuki, T., Kuroiwa, T.: Organelle DNA synthesis in the quiescent centre of Arabidopsis thaliana. (Col). J. Exp. Bot. 44, 690-693 (1993)

Galbraith, D.W., Harkins, K.R., Knapp, S.: Systemic endopolyploidy in Arabidopsis thaliana. Plant Physiol. 96(3), 985-989 (1991)

Hernandez-Verdun, D.: Nucleolus: from structure to dynamics. Histochem. Cell Biol. 125(1-2), 127-137 (2006). doi:10. 1007/S00418-005-0046-4

Hilaire, E., Peterson, B.V., Guikema, J.A., Brown, C.S.: Clinorotation affects morphology and ethylene production in soybean seedlings. Plant Cell Physiol. 37(7), 929-934 (1996)

Hoson, T., Matsumoto, S., Soga, K., Wakabayashi, K.: Cortical microtubules are responsible for gravity resistance in plants. Plant Signal Behav. 5(6), 752-754 (2010)

Ingber, D.E.: Cellular mechanotransduction: putting all the pieces together again. FASEB J. 20(7), 811-827 (2006). doi:10.1096/Fj.05-5424rev

Matía, I., Van Loon, J.J.W.A., Carnero-Díaz, E., Marco, R., Medina, F.J.: Seed germination and seedling growth under simulated microgravity causes alterations in plant cell proliferation and ribosome biogenesis. Microgravity Sci. Technol. 21, 169-174 (2009). doi:10.1007/S12217-008-9069-5

Matía, I., González-Camacho, F., Herranz, R., Kiss, J.Z., Gasset, G., Van Loon, J.J.W.A., Marco, R., Medina, F.J.: Plant cell proliferation and growth are altered by microgravity conditions in spaceflight. J. Plant Physiol. 167(3):184-193 (2010). doi:10.1016/J.Jplph.2009.08.012

Medina, F.J., Herranz, R.: Microgravity environment uncouples cell growth and cell proliferation in root meristematic cells: the mediator role of auxin. Plant Signal Behav. 5(2), 176-179 (2010)

Medina, F.J., Cerdido, A., De Cárcer, G.: The functional organization of the nucleolus in proliferating plant cells. Eur. J. Histochem. 44, 117-131 (2000)

Mizukami, Y.: A matter of size: developmental control of organ size in plants. Curr. Opin. Plant Biol. 4(6), 533-539 (2001)

Monshausen, G.B., Sievers, A.: Basipetal propagation of gravityinduced surface $\mathrm{Ph}$ changes along primary roots of Lepidium Sativum L. Planta 215, 980-988 (2002)

Nickerson, C.A., Ott, C.M., Wilson, J.W., Ramamurthy, R., Pierson, D.L.: Microbial responses to microgravity and other low-shear environments. Microbiol. Mol. Biol. Rev. 68(2), 345-361 (2004). doi:10.1128/Mmbr.68.2.345-361.2004 
Raska, I., Shaw, P.J., Cmarko, D.: Structure and function of the nucleolus in the spotlight. Curr. Opin. Cell Biol. 18(3), 325334 (2006). doi:10.1016/J.Ceb.2006.04.008

Sáez-Vasquez, J., Medina, F.J.: The plant nucleolus. Advances in botanical research. Incorp. Adv. Plant Pathol. 47, 1-46 (2008)

Scheres, B., Benfey, P., Dolan, L.: Root development. The arabidopsis book. Am. Soc. Plant Biol. (2002). doi:10.1199/ tab.0101

Schnittger, A., Schobinger, U., Stierhof, Y.D., Hulskamp, M.: Ectopic B-type cyclin expression induces mitotic cycles in endoreduplicating arabidopsis trichomes. Curr. Biol. 12(5), 415-420 (2002)

Shaw, P., Doonan, J.: The nucleolus. Playing by different rules? Cell Cycle 4(1), 102-105 (2005)

Skirycz, A., Claeys, H., De Bodt, S., Oikawa, A., Shinoda, S., Andriankaja, M., Maleux, K., Eloy, N.B., Coppens, F., Yoo, S.D., Saito, K., Inze, D.: Pause-and-stop: the effects of osmotic stress on cell proliferation during early leaf development in arabidopsis and a role for ethylene signaling in cell cycle arrest. Plant Cell 23(5), 1876-1888 (2011). doi:10.1105/Tpc.111.084160

Soga, K.: Perception mechanism of gravistimuli in gravity resistance responses of plants. Biol. Sci. Space 18(3), 92-93 (2004)

Soga, K., Wakabayashi, K., Hoson, T., Kamisaka, S.: Hypergravity increases the molecular mass of xyloglucans by decreasing xyloglucan-degrading activity in Azuki bean epicotyls. Plant Cell Physiol. 40, 581-585 (1999)

Soto, T., Nunez, A., Madrid, M., Vicente, J., Gacto, M., Cansado, J.: Transduction of centrifugation-induced gravity forces through mitogen-activated protein kinase path ways in the fission yeast schizosaccharomyces Pombe. Microbiology 153(Pt 5), 1519-1529 (2007). doi:10.1099/Mic.0. 2006/004283-0

Suzuki, T., Nakajima, S., Inagaki, S., Hirano-Nakakita, M., Matsuoka, K., Demura, T., Fukuda, H., Morikami, A., Nakamura, K.: Tonsoku is expressed in $\mathrm{S}$ phase of the cell cycle and its defect delays cell cycle progression in arabidopsis. Plant Cell Physiol. 46, 736-742 (2005)

Tamaoki, D., Karahara, I., Schreiber, L., Wakasugi, T., Yamada, K., Kamisaka, S.: Effects of hypergravity conditions on elongation growth and lignin formation in the inflorescence stem of Arabidopsis thaliana. J. Plant Res. 119(2), 79-84 (2006). doi:10.1007/S10265-005-0243-1

Thiry, M., Goessens, G.: The Nucleolus During the Cell Cycle. Landes Bioscience, Georgetown (1996)

Van Loon, J.J.W.A.: Some history and use of the random positioning machine, Rpm, in gravity related research. Adv. Space. Res. 39, 1161-1165 (2007)

Van Loon, J.J.W.A., Krause, J., Cunha, H., Goncalves, J., Almeida, H., Schiller, P.: The large diameter centrifuge, Ldc, for life and physical sciences and technology. In: Proceedings of the 'Life in Space for Life on Earth Symposium', Angers, France, 22-27 June 2008 (Esa Sp-663, December 2008)

Weingartner, M., Criqui, M.C., Meszaros, T., Binarova, P., Schmit, A.C., Helfer, A., Derevier, A., Erhardt, M., Bogre, L., Genschik, P.: Expression of a nondegradable cyclin B1 affects plant development and leads to endomitosis by inhibiting the formation of a phragmoplast. Plant Cell 16(3), 643-657 (2004). doi:10.1105/Tpc.020057 